\title{
Nutlin-3 preferentially sensitises wild-type p53-expressing cancer cells to DR5-selective TRAIL over rhTRAIL
}

\begin{abstract}
A Meijer ${ }^{1}$, F A E Kruyt ${ }^{1}$, A G J van der Zee ${ }^{2}, \mathrm{H} \mathrm{Hollema}^{3}, \mathrm{P} \mathrm{Le}{ }^{1}, \mathrm{~K}$ A ten Hoor ${ }^{2}, \mathrm{G} \mathrm{M} \mathrm{M} \mathrm{Groothuis}{ }^{4}$, W J Quax ${ }^{5}$, E G E de Vries ${ }^{1}$ and S de Jong ${ }^{\star, 1}$

${ }^{1}$ Department of Medical Oncology, Cancer Research Center Groningen, University of Groningen, University Medical Centre Groningen, Groningen, The Netherlands; ${ }^{2}$ Department of Gynecologic Oncology, Cancer Research Center Groningen, University of Groningen, University Medical Centre Groningen, Groningen, The Netherlands; ${ }^{3}$ Department of Pathology, Cancer Research Center Groningen, University of Groningen, University Medical Centre Groningen, Groningen, The Netherlands; ${ }^{4}$ Department of Pharmacy, Toxicology and Targeting, Groningen Research Institute for Pharmacy, University of Groningen, Groningen, The Netherlands and ${ }^{5}$ Department of Pharmaceutical Biology, Groningen Research Institute for Pharmacy, University of Groningen, Groningen, The Netherlands
\end{abstract}

Background: Tumour cell-selective activation of apoptosis by recombinant human TNF-related apoptosis-inducing ligand (rhTRAIL) is enhanced through co-activation of p53 by chemotherapeutic drugs. The novel anticancer agent nutlin-3 provides a promising alternative for p53 activation by disrupting the interaction between p53 and its negative feedback regulator MDM2.

Methods: We examined whether nutlin-3 enhances apoptosis induction by rhTRAIL and the DR5-selective TRAIL variant D269H/E195R in wild-type p53-expressing ovarian, colon and lung cancer cell lines and in an ex vivo model of human ovarian cancer.

Results: Nutlin-3 enhanced p53, p21, MDM2 and DR5 surface expression. Although nutlin-3 did not induce apoptosis, it preferentially enhanced D269H/E195R-induced apoptosis over rhTRAIL. Combination treatment potentiated the cleavage of caspases 8, 9, 3 and PARP. P53 and MDM2 siRNA experiments showed that this enhanced apoptotic effect was mediated by wildtype p53. Indeed, nutlin-3 did not enhance rhTRAIL-induced apoptosis in OVCAR-3 cells harbouring mutant p53. Addition of the chemotherapeutic drug cisplatin to the combination further increased p53 and DR5 levels and rhTRAIL- and D269H/E195Rinduced apoptosis. As a proof of concept, we show that the combination of D269H/E195R, nutlin-3 and cisplatin induced massive apoptosis in ex vivo tissue slices of primary human ovarian cancers.

Conclusion: Nutlin-3 is a potent enhancer of D269H/E195R-induced apoptosis in wild-type p53-expressing cancer cells. Addition of DNA-damaging agents such as cisplatin further enhances DR5-mediated apoptosis.

Cancer remains one of the leading causes of death in developed countries and cancer mortality is expected to continue to rise globally, so new drugs are urgently required. An abundance of cancer drugs, often molecularly targeted and rationally designed, are currently becoming available for use in the clinic. Many of the newly developed targeted drugs will exert only modest activity when applied alone and will be more effective when combined with other drugs. Examination of rationalised combinations and optimising their antitumour activity is therefore highly relevant to improve therapy.

*Correspondence: Dr S de Jong; E-mail: s.de.jong@umcg.nl

Received 23 March 2013; revised 20 September 2013; accepted 24 September 2013; published online 17 October 2013

(c) 2013 Cancer Research UK. All rights reserved 0007-0920/13 
An example of a drug with clear preclinical activity and modest activity in the clinic is recombinant human TNF-related apoptosisinducing ligand (rhTRAIL) or Dulanermin. It can bind to proapoptotic TRAIL death receptors, designated death receptor DR4 or TRAIL-R1 and DR5 or TRAIL-R2, leading to selective apoptosis induction in tumour cells, while leaving normal cells unharmed (Wiley et al, 1995; Pitti et al, 1996; Ashkenazi et al, 1999; Herbst et al, 2010; Soria et al, 2011). DR-specific agonistic antibodies and rhTRAIL variants have been generated to specifically target one TRAIL death receptor to enhance efficacy (Ichikawa et al, 2001; Kelley et al, 2005; Pukac et al, 2005; van der Sloot et al, 2006; Adams et al, 2008; Li et al, 2008; Tur et al, 2008; Reis et al, 2009, 2010). For example, E195R/D296H, a DR5-selective variant of rhTRAIL, has increased affinity for DR5 and was a more effective apoptosis inducer as compared with rhTRAIL in various cell lines and in a bioluminescent xenograft model of ovarian cancer (van der Sloot et al, 2006; Duiker et al, 2009). The efficacy of rhTRAIL-induced apoptosis can be further enhanced by a rational combination of drugs targeting complementary apoptotic pathways (Hougardy et al, 2005; Duiker et al, 2009; Mahalingam et al, 2009).

RhTRAIL activates the extrinsic apoptotic pathway in which binding to DR4 and DR5 results in the formation of the deathinducing signalling complex (DISC), comprising Fas-associated death domain (FADD) and caspase 8 (Walczak and Sprick, 2001). Following DISC formation, caspase 8 is cleaved, leading to either direct activation of caspase 3 or engagement of the intrinsic (mitochondrial) apoptotic pathway via Bid cleavage, leading to caspase 3 activation and eventually to apoptosis. Chemotherapeutic drugs and radiation, in general, induce the intrinsic apoptotic pathway that involves DNA damage-induced activation of signalling proteins including the tumour suppressor protein p53. P53, an important transcription factor, subsequently triggers cell cycle arrest and/or apoptosis via p53-mediated release of apoptotic factors from the mitochondria leading to cleavage of caspases 9 and 3 (Adams and Cory, 2007; Vousden and Lane, 2007). Combination of rhTRAIL with chemotherapeutic drugs thus results in simultaneous activation of the extrinsic and intrinsic apoptotic pathways, leading to strong apoptosis in tumour cells in preclinical models (Mahalingam et al, 2009). In the clinic, data have been reported regarding a patient with refractory chondrosarcoma who showed a partial response to treatment with Dulanermin as a single agent (Subbiah et al, 2012). However, phase 2 randomised studies have not yet shown a clear advantage of the addition of rhTRAIL or death receptor-targeting antibodies to chemotherapy (den Hollander et al, 2013).

Therefore, an even more pronounced exploitation of the intrinsic pathway might be relevant. In this respect, the recently developed drug nutlin-3 is of interest. Nutlin-3 is a small molecule that binds MDM2, which is a negative feedback regulator of p53 activity by forming a complex with p53. In addition, MDM2 in complex with p53 can induce proteasomal degradation of p53. Disruption of the MDM2-p53 interaction by nutlin-3 results in accumulation of p53 in the absence of DNA damage. Nutlin-3 effectively induced p53 levels in a panel of cancer cell lines carrying wild-type p53, resulting in apoptosis or cell cycle arrest in vitro as well as in vivo (Ashcroft and Vousden, 1999; Vassilev et al, 2004; Bond et al, 2005; Tovar et al, 2006). Nutlin-3 is currently in early clinical development and might especially be of interest for the $50 \%$ of the tumours that carry wild-type p53 (Brown et al, 2009; Levine and Oren, 2009).

In the present study, we have used nutlin-3 as a novel approach to activate $\mathrm{p} 53$ and the intrinsic apoptotic pathway in a panel of wild-type p53-expressing human cancer cell lines. Next, we explored the effect of combining nutlin-3 and extrinsic apoptotic pathway activation by rhTRAIL. We compared the apoptosisinducing ability of rhTRAIL $v$ s the DR5-selective TRAIL variant
D269H/E195R when combined with nutlin-3. Finally, an innovative living ex-patient model of primary human ovarian cancers was included to test the functionality of TRAIL receptor-targeting drugs and nutlin-3 in combination with cisplatin in a clinically more relevant context.

\section{MATERIALS AND METHODS}

Reagents. RhTRAIL and D269H/E195R were produced as described earlier (van der Sloot et al, 2006). Nutlin-3 was purchased from Cayman Chemical (Huissen, the Netherlands) and caspase inhibitor 1 (zVAD-FMK) from Calbiochem (via Omnilabo, Breda, the Netherlands).

Cell culture. The human ovarian cancer cell line A2780 was kindly provided by Dr TC Hamilton (Fox Chase Cancer Center, Philadelphia, USA). The human H460 non-small cell lung cancer, the human Lovo colon cancer and the human OVCAR-3 ovarian cancer cell lines were purchased from American Type Culture Collection. A2780, H460 and Lovo carry wild-type p53, whereas OVCAR-3 carries mutant p53. A2780 was cultured in RPMI 1640 (Gibco, Paisley, Scotland), supplemented with $10 \%$ heat-inactivated fetal calf serum (FCS) (Bodinco BV, Alkmaar, the Netherlands) and $0.1 \mathrm{M}$ L-glutamine, H460 and Lovo in RPMI 1640, supplemented with $10 \%$ heat-inactivated FCS, OVCAR-3 in DMEM high glucose (Invitrogen, Breda, the Netherlands), supplemented with $10 \%$ heat-inactivated FCS and $0.1 \mathrm{M}$ L-glutamine. All cell lines grew as monolayers and were cultured in a humidified atmosphere with $5 \% \mathrm{CO}_{2}$.

Cytotoxicity assay. The microculture tetrazolium assay was used to measure cytotoxicity. Cell lines were cultured in HAM/F12 and DMEM medium, supplemented with $20 \%$ FCS and $0.1 \mathrm{M}$ L-glutamine. Following $96 \mathrm{~h}$ treatment, 3-(4,5-dimethylthiazol-2yl)-2,5-diphenyltetrazoliumbromide (MTT)-solution at a concentration of $5 \mathrm{mg} \mathrm{ml}^{-1}$ (Sigma-Aldrich Chemie BV, Zwijndrecht, the Netherlands) was added and formazan production was measured as described previously (Timmer-Bosscha et al, 1993). Cell survival was defined as the growth of treated cells compared with untreated cells and was determined in three experiments with each performed in quadruplicate.

Determination of apoptosis. Cells were seeded in 96-well plates and treated as indicated. Following treatment, apoptosis was identified by staining nuclear chromatin with acridine orange. Apoptosis was defined by the appearance of apoptotic bodies and/ or chromatin condensation by fluorescence microscopy and was expressed as the percentage of apoptotic cells in a well. All experiments were performed at least three times.

Western blot analysis. Cells were seeded in six-well plates and treated as indicated. Following treatment, cells were harvested at indicated time points by treatment with trypsin for $5 \mathrm{~min}$ at $37^{\circ} \mathrm{C}$ and washed twice with cold PBS. Cells were lysed for $30 \mathrm{~min}$ on ice with M-PER lysis buffer (Pierce, Rockford, IL, USA) supplemented with protease inhibitor followed by centrifugation (10 min $10000 \mathrm{~g}$, $4{ }^{\circ} \mathrm{C}$ ). Subsequently, protein concentrations were determined using a Bio-Rad DC protein assay according to the manufacturers' protocol (Bio-Rad, Veenendaal, the Netherlands) and cell lysates were diluted to $1 \mu \mathrm{g} \mu \mathrm{l}^{-1}$ with $2 \times$ SDS sample buffer $(50 \mathrm{~mm}$ Tris- $\mathrm{HCl}$ (pH 6.8), 4\% SDS, $10 \%$ glycerol, $10 \%$ 2- -3 -mercaptoethanol, $0.002 \%$ bromophenol blue) and boiled for $5 \mathrm{~min}$. Total cell lysates were size-fractionated on sodium dodecyl sulfate-polyacrylamide gel electrophoresis (SDS-PAGE) and transferred onto activated polyvinylidene difluoride membranes (Millipore BV, Bedford, UK). After blocking for $1 \mathrm{~h}$ in Tris-buffered saline (mM Tris- $\mathrm{HCl}, 137 \mathrm{~mm} \mathrm{NaCl}_{2}$ ) supplemented with 5\% milk powder (Merck, Darmstadt, Germany) and 0.05\% Tween-20 
(Sigma-Aldrich), immunodetection of the protein of interest was performed according to the manufacturer's protocol. The following antibodies were applied: caspase 3 (9662), cleaved caspase 3 (9661), caspase 8 (9746), caspase 9 (9502), PUMA (4976), DR5 (3696) (all from Cell Signaling, Leusden, the Netherlands), p53 (DO-1, Santa Cruz, Heerhugowaard, the Netherlands), p21/waf1 (OP64), MDM2 (Ab-1) (both from Calbiochem), noxa (ALX-804-408, Alexis, Lausen, Switzerland), DR5 (ALX-210-743-c200, Alexis) and PARP (11 835238 001, Roche Diagnostics, Almere, the Netherlands). The Bid antibody was kindly provided by Dr J Borst (the Netherlands Cancer Institute, Amsterdam, the Netherlands). Binding of these antibodies was determined using horseradish peroxidase (HRP)-conjugated secondary rabbit anti-mouse and goat anti-rabbit antibodies (DAKO, Glostrup, Denmark). Visualisation was performed with LumiLight Plus Western Blotting Substrate (Roche Diagnostics). Equal protein loading was confirmed by immunostaining with $\beta$-actin antibody (mouse, A5441; Sigma-Aldrich). All experiments were performed at least three times.

Flow cytometry. Cells were seeded in six-well plates and treated as indicated. After treatment, cells were harvested at indicated time points by treatment with cell dissociation buffer (Gibco) for $5 \mathrm{~min}$ at $37^{\circ} \mathrm{C}$ and washed twice with cold PBS supplemented with $2 \%$ FCS and $0.1 \%$ sodium azide. The following antibodies were used to determine TRAIL receptor membrane expression: TRAIL-R1 (HS101), TRAIL-R2 (HS201), TRAIL-R3 (HS301), TRAIL-R4 (HS402) (all purchased from Alexis) and phycoerythrin (PE)conjugated goat anti-mouse. Mouse IgG (Dako) was used as isotype control. TRAIL receptor membrane expression was analysed using a flow cytometer (FACSCalibur, Becton Dickinson Biosciences, Franklin Lakes, NJ, USA) and is shown as mean fluorescent intensity (MFI) of all analysed cells from at least three separate experiments.

RNA interference. Small interfering RNAs (siRNAs) specific for p53, MDM2 and Bid were designed. The double-stranded sequences were: $5^{\prime}$ AAGACUCCAGUGGUAAUCUAC-dTdT3' (sense) and 5'GUAGAUUACCACUGGAGUCUU-dTdT3' (antisense) for p53, 5'AAGCCAUUGCUUUUGAAGUUA-dTdT3' (sense) and 5'UAACUUCAAAAGCAAUGGCUU-dTdT3' (antisense) for MDM2, and 5'GAAUAGAGGCAGAUUCUGA-dTdT3' (sense) and 5'UCAGAAUCUGCCUCUAUUC-dTdT3' (antisense) for Bid. Cells were seeded in six-well plates. The next day, the subconfluent cells were incubated in unsupplemented Optimem medium (Gibco) and transfected with $133 \mathrm{~nm}$ p53, MDM2, Bid or negative control siRNA (Eurogentec, Seraing, Belgium) using Oligofectamine reagent according to the manufacturer's protocol (Invitrogen). Twenty four hours after siRNA treatment, cells were seeded for apoptosis assays or western blot analysis and treated as indicated.

Tissue collection for ex vivo tissue slice experiments. Epithelial ovarian cancer tissue samples were obtained from patients undergoing primary surgery at the UMCG. All histological subtypes were included in the study. All patients gave written informed consent. We assessed 50 specimens for adequacy based on tumour cell content, size of the specimen and tissue consistency, and rejected 41 specimens based on these criteria, mostly due to low or no tumour cell content. Finally, five specimens were used to optimise our protocols and incubation times. Four tumour specimens were used for combination treatments. Tumour specimens obtained from ovaries or omentum were placed on ice-cold medium (DMEM high glucose (Invitrogen) supplemented with $10 \%$ FCS, $1 \%$ penicillin/streptomycin, $2.5 \mu \mathrm{g} \mathrm{ml}^{-1}$ amphotericin B and $50 \mu \mathrm{g} \mathrm{ml}^{-1}$ gentamicin) immediately following surgical resection. Specimens were used for the experiment within a few hours after resection.
Preparation and incubation of tissue slices. Cores of $5 \mathrm{~mm}$ were prepared manually from the obtained tumour specimen, embedded in $2 \%$ agarose (Low-gelling-temperature agarose type VII, SigmaAldrich) and placed in a Krumdieck Tissue Slicer (Alabama Research and Development, Munford, AL, USA). Slicing was performed under buffered conditions in ice-cold oxygen-saturated Krebs-Henseleit buffer (KHB) (supplemented with $25 \mathrm{~mm}$ glucose (Merck), $25 \mathrm{~mm} \mathrm{NaHCO}_{3}$ (Roth, Karlsruhe, Germany), $10 \mathrm{~mm}$ HEPES (Roth), pH 7.4). Tissue slices of $\sim 200-300 \mu \mathrm{m}$ thickness and a wet weight of $10-14 \mathrm{mg}$ were generated using standard settings (cycle speed setting 30; interrupted mode) and collected in ice-cold KHB. Within $1 \mathrm{~h}$ after slicing, three slices were fixed in formalin to serve as $0 \mathrm{~h}$ controls and the other slices were incubated individually in six-well plates in oxygen-saturated medium (DMEM high glucose (Invitrogen) supplemented with $10 \%$ FCS, $1 \%$ penicillin/streptomycin, $2.5 \mu \mathrm{g} \mathrm{ml}^{-1}$ amphotericin B and $50 \mu \mathrm{g} \mathrm{ml}^{-1}$ gentamicin). Plates were placed in plastic containers allowing constant gassing with carbogen and incubated at $37^{\circ} \mathrm{C}$, while gently shaking (de Graaf et al, 2010). Depending on the number of slices that could be obtained, drug combinations were added in triplicates as indicated after $1 \mathrm{~h}$ incubation. Following $24 \mathrm{~h}$ treatment, slices were fixed in formalin and paraffin-embedded. Sections $(4 \mu \mathrm{m})$ were cut from the paraffinembedded slices, mounted on APES-coated slides, deparaffinised by standard procedure and stained with hematoxylin-eosin (H\&E). Apoptosis was cytomorphologically scored based on H\&E staining as described earlier (Hougardy et al, 2008).

Immunohistochemistry. Sections were immunohistochemically stained for cleaved caspase 3 with a polyclonal rabbit anti-cleaved caspase 3 antibody (3661, Cell Signaling) as described previously (Hougardy et al, 2008).

Statistical analysis. All experiments were performed independently at least three times, except otherwise indicated. Data are represented as the mean \pm s.d. Statistical analyses were performed using two-tailed Student's $t$-test. Two-tailed $P$-values $<0.05$ were considered significant.

\section{RESULTS}

Nutlin-3 increased p53, p21, MDM2 protein levels, and DR5 surface expression. We used wild-type p53-expressing human cancer cell lines from different tumour types to assess the effect of nutlin-3. A2780 ovarian cancer, Lovo colon cancer and H460 nonsmall cell lung cancer cells were treated for $24 \mathrm{~h}$ with increasing concentrations of nutlin-3 after which p53, p21 and MDM2 protein levels were determined. Nutlin-3 dose-dependently enhanced p53, p21 and MDM2 levels, which indicates transcriptional activation of $\mathrm{p} 53$ due to the effective disruption of the MDM2-p53 interaction (Figure 1A). Next, we investigated whether nutlin-3 affected expression of DR5, a transcriptional target of p53 (Wu et al, 1997). Indeed, DR5 protein levels were increased upon nutlin-3 treatment in these cell lines (Figure 1A). Moreover, DR5 membrane expression of all cell lines increased upon treatment with increasing concentrations of nutlin-3. DR4 membrane expression remained negative in A2780 cells and stable in H460 cells, whereas DR4 membrane expression decreased in Lovo cells. Membrane levels of decoy receptor 2 (DcR2) did not change, whereas decoy receptor 1 (DcR1) levels were not detected in these cell lines (Figure 1B).

Nutlin-3 preferentially enhanced apoptosis induction by D269H/E195R over rhTRAIL. We examined whether enhanced p53 and DR5 expression by nutlin-3 sensitised cells to rhTRAIL 

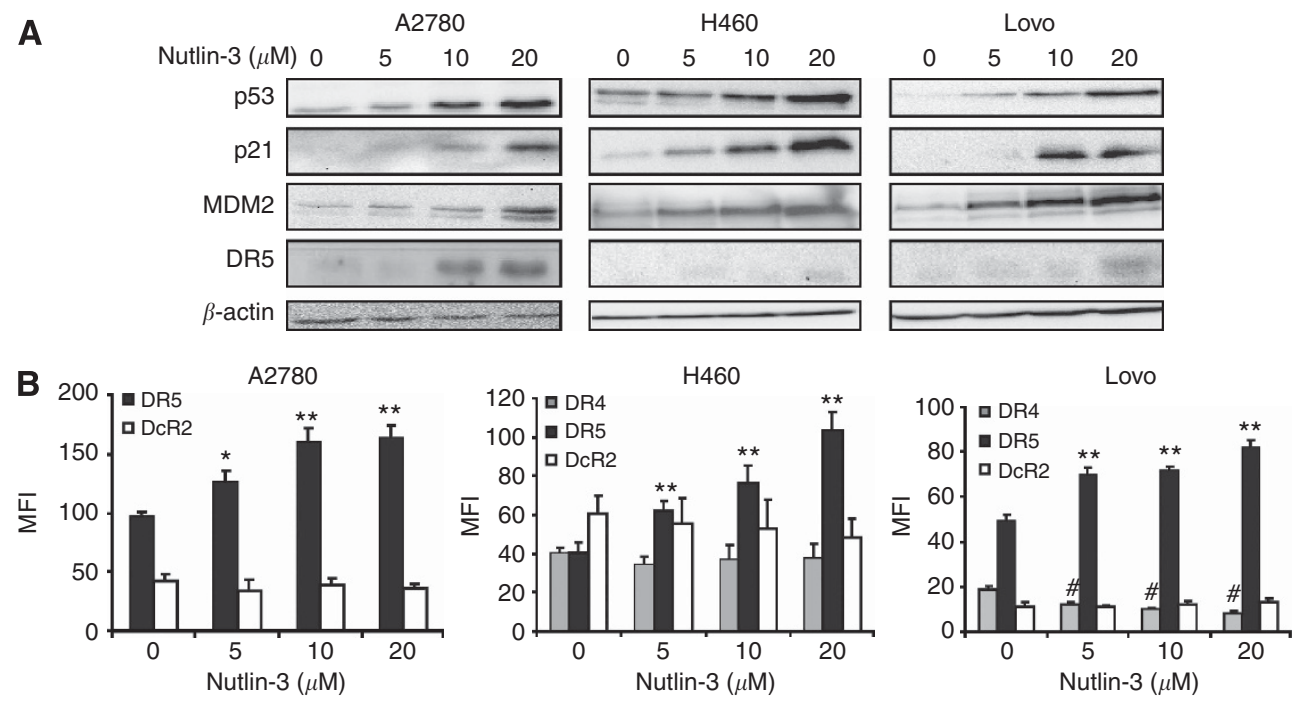

Figure 1. Nutlin-3 treatment induced upregulation of p53, p21, MDM2 and DR5 (membrane) expression. (A) Treatment of A2780, H460 and Lovo with increasing concentrations of nutlin-3 for $24 \mathrm{~h}$ resulted in a dose-dependent upregulation of p53, MDM2, p21 and DR5 protein levels as determined by western blotting. (B) DR4, DR5 and DCR2 membrane expression levels were measured using FACS analysis demonstrating that nutlin-3 enhanced DR5 levels dose-dependently, whereas DcR2 remained unchanged. In H460 and Lovo, DR4 levels decreased upon treatment. DcR1 was not detected. Presented data are representative for at least three independent experiments and mean MFI levels are shown $\pm \mathrm{s}$.d. ${ }^{\star} P<0.05,{ }^{* \star} P<0.01$ compared with DR5 MFI at $0 \mu \mathrm{M}$ nutlin-3. ${ }^{\#} P<0.05$ compared with DcR2 MFI at $0 \mu \mathrm{M}$ nutlin-3.

and D269H/E195R (100 $\left.\mathrm{ng} \mathrm{ml}^{-1}\right)$. Nutlin-3 treatment for $24 \mathrm{~h}$ was not an effective apoptosis inducer in A2780, H460 or Lovo cells. Therefore, A2780 cells were treated for $24 \mathrm{~h}$ with nutlin-3, while either rhTRAIL or D269H/E195R was added during the last $4 \mathrm{~h}$ of treatment. A2780 cells were modestly sensitive to rhTRAIL and more sensitive to D269H/E195R, showing $7 \pm 2 \%$ versus $21 \pm 5 \%$ apoptosis $(P<0.009)$, respectively. The sequential combination of nutlin-3 and rhTRAIL or D269H/E195R strongly increased apoptosis. With $20 \mu \mathrm{M}$ nutlin-3 the increase in apoptosis in A2780 cells was $14.1 \pm 3.6 \%$ with rhTRAIL and $35.2 \pm 6.2 \%$ with D269H/E195R, respectively $(P<0.007$, rhTRAIL vs D269H/ E195R). Interestingly, rhTRAIL induced more apoptosis than $\mathrm{D} 269 \mathrm{H} / \mathrm{E} 195 \mathrm{R}$ in $\mathrm{H} 460$ cells $(32 \pm 4.4 \%$ vs $13 \pm 4.4 \%, P<0.003)$ and in Lovo cells $(29.6 \pm 4.6 \%$ vs $8.1 \pm 0.9 \%, P<0.001)$. Next, H460 and Lovo cells were concomitantly exposed to nutlin-3 and rhTRAIL or nutlin-3 and D269H/E195R for $24 \mathrm{~h}$. The combination of nutlin-3 $(20 \mu \mathrm{M})$ with either rhTRAIL or D269H/E195R resulted in an increase in apoptosis in $\mathrm{H} 460$ cells of $36.1 \pm 5.1 \%$ and $54 \pm 12.7 \%(P=0.09)$, respectively, and in Lovo cells of $28.3 \pm 6.8 \%$ and $43.8 \pm 8.3 \%(P=0.07)$, respectively (Figure $2 \mathrm{~A})$. Summarising, in all cell lines tested the sensitising effect of nutlin-3 on ligandinduced apoptosis was more pronounced in combination with D269H/E195R.

Nutlin-3 combined with rhTRAIL or D269H/E195R enhanced caspase-dependent apoptosis. The molecular mechanism of enhanced apoptosis induction following combination treatment was further analysed in ovarian cancer models. Hence, the effect of single and combined treatment regimens on apoptosis at the level of caspases 8, 9, 3 and PARP cleavage was examined in A2780 cells. Treatment with nutlin-3 $(24 \mathrm{~h})$ or rhTRAIL $(4 \mathrm{~h})$ did not induce caspase or PARP cleavage. D269H/E195R (4h) induced mild cleavage of caspase 8, caspase 9, caspase 3 and PARP. Clearly, cleavage of all three caspases and PARP was strongly induced upon combined nutlin-3 and D269H/E195R treatment, and somewhat less with the combination of nutlin-3 and rhTRAIL (Figure 2B). Apoptosis induction by the combination was caspase-dependent, as pre-incubation $(1 \mathrm{~h})$ with the broad-caspase inhibitor $\mathrm{zVAD}$ -
FMK $(50 \mu \mathrm{M})$ prior to the addition of rhTRAIL or D269H/E195R completely prevented apoptosis induction (Figure 2C).

The sensitising effect of nutlin-3 was dependent on the disruption of the MDM2-p53 interaction. To exclude p53-independent effects of MDM2 that have been described (Zhang and Zhang, 2005), MDM2 was downregulated using siRNA in A2780 cells. Effective downregulation of MDM2 resulted in significantly higher apoptosis levels induced by D269H/E195R and a trend for rhTRAIL (Figure 3A). Nutlin-3 less effectively enhanced apoptosis in MDM2-suppressed cells, in line with the MDM2 dependency of nutlin-3. For instance, treatment with $20 \mu \mathrm{M}$ nutlin-3 caused an increase in rhTRAIL-induced apoptosis of $17.8 \pm 3.1 \%$ in control siRNA-treated A2780 cells and $2.8 \pm 2.6 \%$ in MDM2-suppressed A2780 cells $(P<0.003)$. A comparable effect was observed for D269H/E195R in combination with $20 \mu \mathrm{M}$ nutlin-3, causing an increase in the apoptosis of $38.7 \pm 6.6 \%$ in control siRNA-treated A2780 cells and $20.7 \pm 7.2 \%$ in MDM2suppressed A2780 cells $(P<0.03)$. Next, we assessed using p53 siRNA whether the apoptosis-stimulating effect of nutlin-3 by MDM2 blocking was due to p53 activation. Apoptosis levels following nutlin-3 and rhTRAIL or D269H/E195R in p53suppressed cells were significantly lower at most nutlin-3 concentrations compared with p53-proficient cells (Figure 3B). Using $20 \mu \mathrm{M}$ nutlin-3, an increase in rhTRAIL-induced apoptosis of $17.8 \pm 3.1 \%$ in control siRNA-treated A2780 cells and $8.5 \pm 3.5 \%$ in p53-suppressed A2780 cells $(P<0.025)$ was found. A similar effect was found for D269H/E195R and $20 \mu \mathrm{M}$ nutlin-3, showing an increase in $\mathrm{D} 269 \mathrm{H} / \mathrm{E} 195 \mathrm{R}$-induced apoptosis of $36.1 \pm 4.2 \%$ in control siRNA-treated A2780 cells and $16.7 \pm 2.6 \%$ in p53suppressed A2780 cells $(P<0.005)$, confirming p53 dependency of the nutlin-3 effect. Upon treatment with nutlin-3, OVCAR-3 cells carrying mutant p53 were not sensitised to rhTRAIL or D269H/E195R, while pre-treatment with cisplatin increased the apoptotic effect of both ligands (Supplementary Figure 1A and B). Together, these results indicate that disruption of the MDM2-p53 interaction by nutlin-3 leading to p53 activation is the main mechanism underlying sensitisation for rhTRAIL and D269H/ 
A

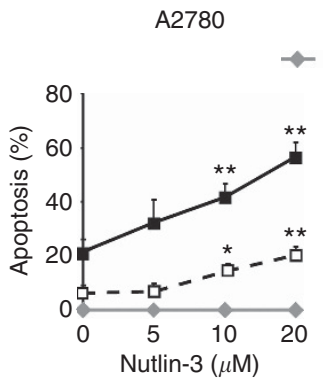

$\checkmark$ Control $\quad$ - - rhTRAll

Lovo
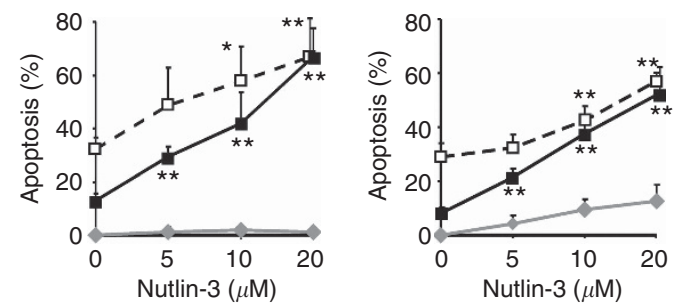

B

Nutlin-3 $(10 \mu \mathrm{M}) \quad-\quad+-\quad++$

C

rhTRAIL (100 $\left.\mathrm{ng} \mathrm{ml}^{-1}\right) \quad-\quad+-+-$

$\mathrm{D} 269 \mathrm{H} / \mathrm{E} 195 \mathrm{R}\left(100 \mathrm{ng} \mathrm{ml}^{-1}\right)-{ }_{-}+-+$

Caspase 8

Cleaved caspase 8 (p18)

Caspase 3

Cleaved caspase 3

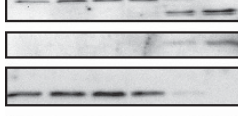

Caspase 9

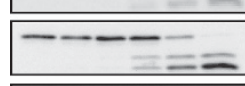

PARP

$\beta$-actin

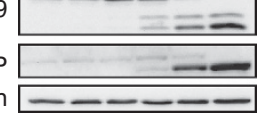

$\mathrm{A} 2780$

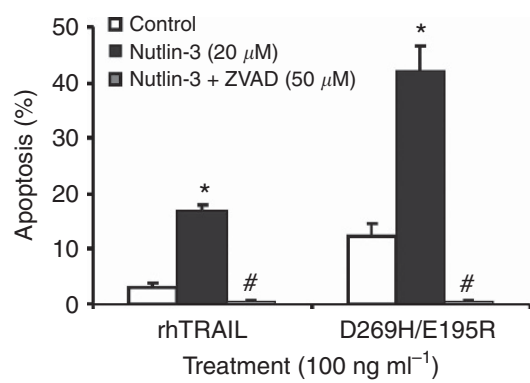

Figure 2. Nutlin-3 enhanced apoptosis induction by rhTRAIL and especially D269H/E195R. (A) Pre-treatment of A2780 cells for $20 \mathrm{~h}$ with increasing concentrations of nutlin-3 followed by addition of rhTRAIL or D269H/E195R for $4 \mathrm{~h}$ dose-dependently increased the percentage of apoptotic cells in particular when using D269H/E195R. Combined treatment for $24 \mathrm{~h}$ dose-dependently sensitised H460 and Lovo to rhTRAIL and $\mathrm{D} 269 \mathrm{H} / \mathrm{E} 195 \mathrm{R}$-induced apoptosis. Apoptosis was determined using an acridine orange assay. ${ }^{\star} P<0.05$, ${ }^{\star \star} P<0.01$ compared with $0 \mu \mathrm{m}$ nutlin-3. (B) Combination treatment with nutlin-3 (24 h) and rhTRAIL or D269H/E195R (4 h) resulted in caspase activation and PARP cleavage, with strongest activation following nutlin-3 and D269H/E195R. (C) Apoptosis induction by the combination was completely blocked by $1 \mathrm{~h}$ pre-treatment with ZVAD-FMK $(50 \mu \mathrm{M})$. ${ }^{*} P<0.01$ compared with $0 \mu \mathrm{m}$ nutlin, ${ }^{\#} P<0.01$ compared with $0 \mu \mathrm{m}$ nutlin-3 and $20 \mu \mathrm{m}$ nutlin-3. Presented data are representative for at least three independent experiments.
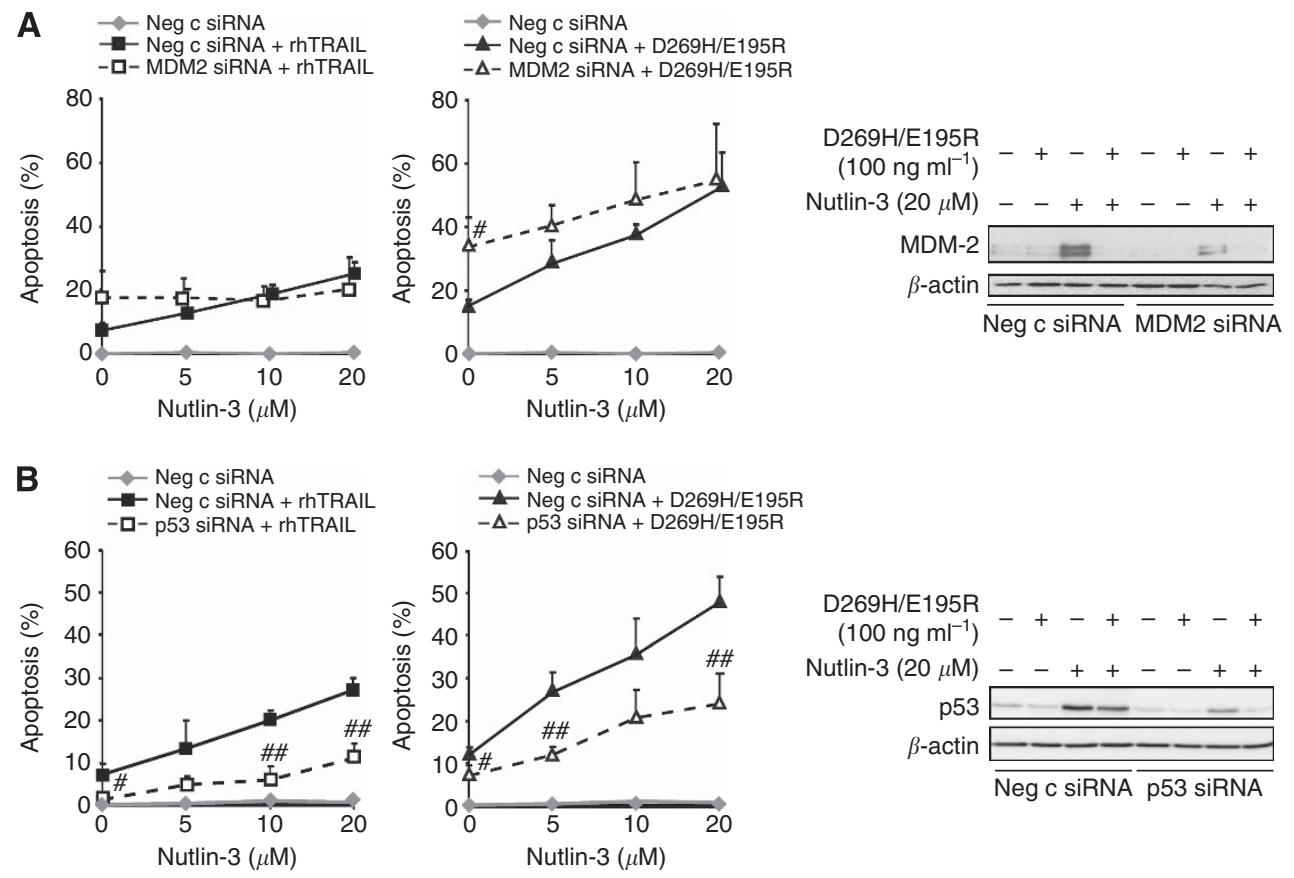

Figure 3. The sensitising effect of nutlin-3 on rhTRAIL- or D269H/E195R-induced apoptosis was exerted via a specific block of the MDM2-p53 interaction. A2780 cells were transfected with MDM2- or p53-specific siRNAs and $48 \mathrm{~h}$ after transfection, cells were treated with the nutlin-3 and rhTRAIL or D269H/E195R combinations. Apoptosis induction was determined by acridine orange. (A) MDM2 was effectively silenced (right panel) and caused sensitisation of cells to rhTRAIL and D269H/E195R, while the sensitising effect of nutlin-3 was abrogated (left panel). (B) P53 was effectively silenced (right panel) and decreased the sensitising effect of nutlin-3 at different concentrations (left panel). ${ }^{\#} P<0.05$, ${ }^{\# \#} P<0.01$ compared with nutlin-3-treated negative control siRNA. Presented data are representative for at least three independent experiments. 

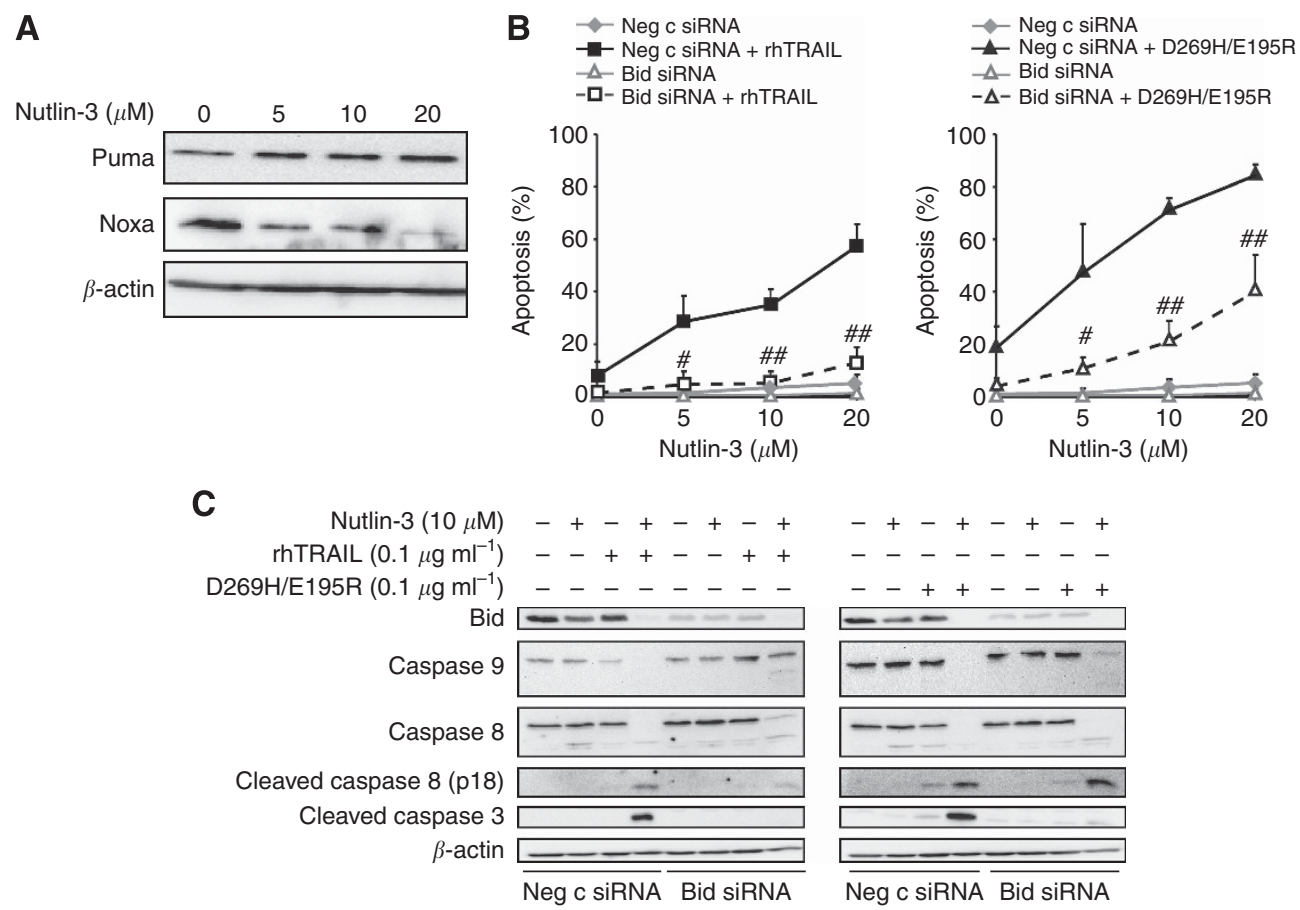

Figure 4. Nutlin-3 in combination with rhTRAIL or D269H/E195R activated apoptosis via Bid. (A) Treatment of cells for $24 \mathrm{~h}$ with increasing concentrations of nutlin-3 hardly affected PUMA expression and caused a decrease in Noxa protein levels. (B) Silencing of Bid by siRNA completely attenuated the sensitising effect of nutlin-3 on rhTRAIL-induced apoptosis (left panel). Nutlin-3-dependent sensitisation for $\mathrm{D} 269 \mathrm{H} / \mathrm{E} 195 \mathrm{R}$ was not completely blocked under these conditions (right panel). ${ }^{\#} P<0.05,{ }^{\# \#} P<0.01$ compared with nutlin-3-treated negative control siRNA. (C) Bid downregulation inhibited caspase 3 and caspase 9 cleavage as induced by combined treatments. Cleavage of caspase 8 was not affected. Presented data are representative for at least three independent experiments.

E195R. Moreover, the sensitising effect of cisplatin appears to involve a p53-independent mechanism.

Nutlin-3 in combination with rhTRAIL or D269H/E195R activated apoptosis via Bid. In order to investigate whether nutlin-3 activated the intrinsic apoptotic pathway, we examined the effect of nutlin-3 on protein levels of PUMA and Noxa, known to be regulated by 553 . PUMA levels were not affected by nutlin-3 and Noxa levels even decreased in A2780 (Figure 4A). Next, Bid was silenced with selective siRNA to block caspase 8-mediated activation of the intrinsic apoptosis pathway following rhTRAIL treatment. Efficient downregulation of Bid (Figure 4C) almost completely prevented apoptosis induction by the combination of rhTRAIL or D269H/E195R with nutlin-3 (Figure 4B). This is illustrated by the lowered rhTRAIL and D269H/E195R-induced apoptosis levels in Bid-suppressed A2780 cells compared with control siRNA-treated A2780 cells pretreated with $20 \mu \mathrm{M}$ nutlin-3 $(11.3 \pm 4.5 \%$ vs $51.3 \pm 1.5 \%, P<0.0001$ for rhTRAIL; $36 \pm 11.4 \%$ $v s 67.3 \pm 11.7 \%, P<0.029$ for $\mathrm{D} 269 \mathrm{H} / \mathrm{E} 195 \mathrm{R})$. The reduction in apoptosis in Bid siRNA-treated cells compared with negative control siRNA-treated cells was reflected in the strong reduction in cleavage of caspases 9 and 3. Cleavage of caspase 8 , however, was hardly affected by Bid downregulation, indicating that caspase 8 activation was not due to a functional feedback of caspase 3/9 (Figure 4C). Together, our data show that nutlin-3 sensitises A2780 cells to rhTRAIL and D269H/E195R by enhanced caspase 8 activation, which facilitates truncated Bid-dependent activation of the intrinsic apoptotic pathway that is essential for apoptosis in these cells.

Cisplatin augmented nutlin-3-induced p53 activation and DR5-mediated apoptosis. Platinum-based chemotherapy is the standard of care for ovarian cancer. Therefore, we examined whether cisplatin could further enhance the effect of nutlin-3 in combination with rhTRAIL and D269H/E195R. A2780 cells were pretreated for $4 \mathrm{~h}$ with cisplatin, washed and further incubated for $16 \mathrm{~h}$ with nutlin-3 to allow maximal p53 induction following cisplatin-induced DNA damage. In A2780, $1 \mu \mathrm{M}$ of cisplatin was sufficient to induce p53, rendering cells more susceptible to nutlin3 treatment, as demonstrated by a stronger induction of p53, p21 and MDM2 compared with single treatment with nutlin-3 or cisplatin (Figure 5A). Notably, although p53 induction is far more pronounced following cisplatin as opposed to nutlin-3 treatment, the level of p21 and MDM2 induction is similar.

Low concentrations of cisplatin $(0.1-2.5 \mu \mathrm{M})$ combined with nutlin-3 $(10 \mu \mathrm{M})$ additively increased DR5 membrane expression levels as compared with single-agent-induced levels, whereas DcR2 levels remained unchanged (Figure 5B). Next, we examined whether cisplatin enhanced the apoptotic effect of nutlin-3 and rhTRAIL or D269H/E195R. Sequential treatment with cisplatin and nutlin-3, as described before, did not induce apoptosis, whereas nutlin-3 enhanced apoptosis induction by D269H/E195R and rhTRAIL ( $4 \mathrm{~h})$. A low dose of cisplatin $(1 \mu \mathrm{M})$ sensitised A2780 to D269H/E195R but not to rhTRAIL. Triple combination of nutlin-3 and cisplatin with D269H/E195R was more potent than D269H/E195R combined with nutlin-3 or cisplatin (Figure 5C). A higher dose of cisplatin $(10 \mu \mathrm{M})$ was required to sensitise cells to rhTRAIL and the triple combination with rhTRAIL then showed additively enhanced apoptosis levels (Supplementary Figure 2A).

Cell survival was also measured following $96 \mathrm{~h}$ combined treatment. Our results indicate that nutlin-3 inhibited cell survival. Moreover, nutlin-3 significantly potentiated cell survival inhibition by D269H/E195R and rhTRAIL (Figure 5D upper panel and Supplementary Figure 2B). Combining a low concentration of nutlin-3 with a low concentration of cisplatin further reduced cell survival (Supplementary Figure 2B). A significantly stronger decrease in cell survival was observed upon combined cisplatin, nutlin-3 and D269H/E195R treatment compared with combined 
A

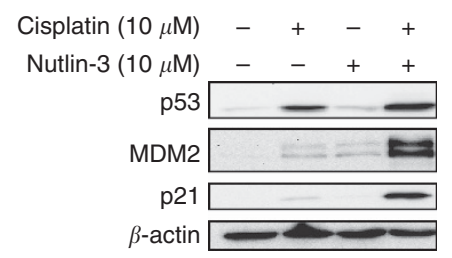

C

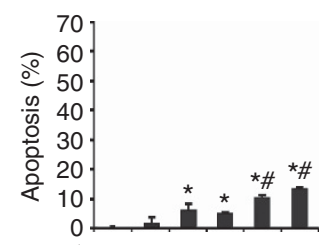

rhTRAIL (100 $\left.\mathrm{ng} \mathrm{ml}^{-1}\right)-{ }_{-}+++$ Nutlin-3 $(10 \mu \mathrm{M})-+--++$ Cisplatin $(1 \mu \mathrm{M})-+-+-+$

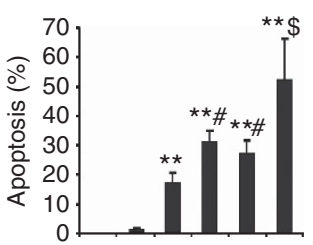

$\mathrm{D} 269 \mathrm{H} / \mathrm{E} 195 \mathrm{R}\left(100 \mathrm{ng} \mathrm{ml}^{-1}\right)--++++$ Nutlin-3 $(10 \mu \mathrm{M})-+--++$ Cisplatin $(1 \mu \mathrm{M})-+-+-+$

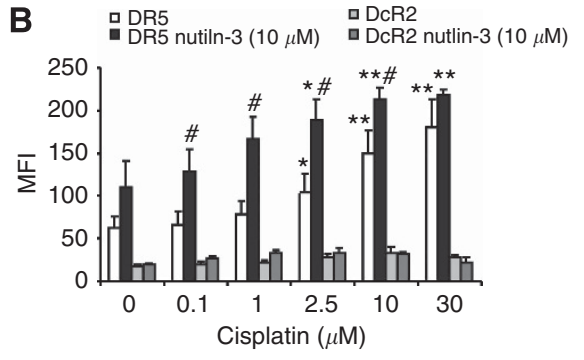

D $\longrightarrow$ Control
$\rightarrow-$ Nutlin-3 $(1 \mu \mathrm{M}) \stackrel{\Delta-\text { Nutlin-3 }(2.5 \mu \mathrm{M})}{\longrightarrow}$ Nutlin-3 $(5 \mu \mathrm{M})$
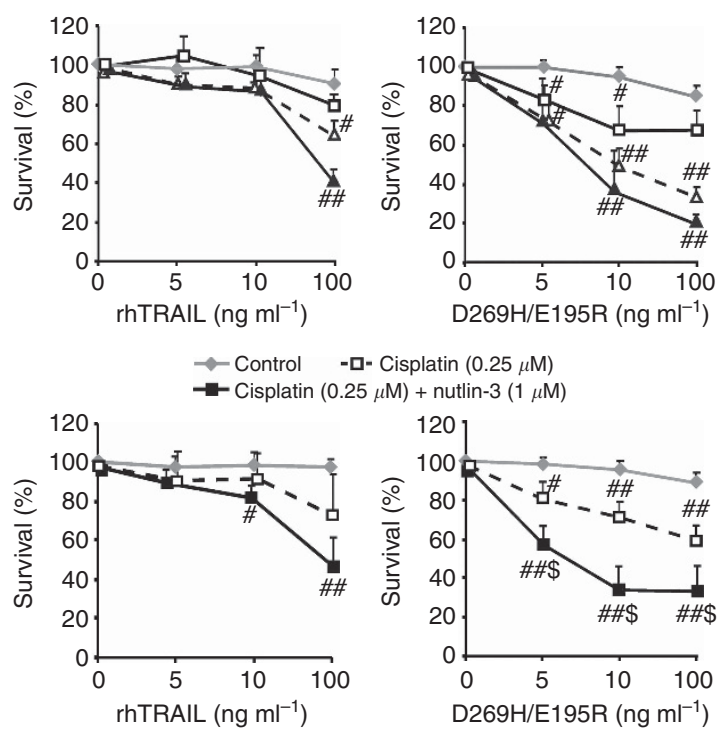

- - Cisplatin $(0.25 \mu \mathrm{M})$

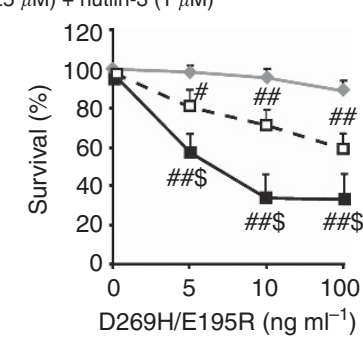

Figure 5. Cisplatin augmented nutlin-3-induced p53 activation and DR5-mediated apoptosis. A2780 cells were pretreated for $4 \mathrm{~h}$ with low doses of cisplatin and after removal of cisplatin treated with nutlin-3 overnight. (A) P53, p21 and MDM2 levels were examined using western blotting. This showed that cisplatin $(10 \mu \mathrm{m})$ combined with nutlin-3 $(10 \mu \mathrm{m})$ induces a massive upregulation of these proteins. (B) DR5 and DcR2 membrane expression levels were determined by FACS analysis and showed that low doses of cisplatin combined with nutlin-3 (10 $\mu \mathrm{M})$ enhanced DR5 levels when compared with nutlin-3 alone. DcR2 levels, however, remained unchanged. ${ }^{\star} P<0.05$, ${ }^{\star \star} P<0.01$ compared with DR5 MFI at $0 \mu \mathrm{M}$ cisplatin. ${ }^{\#} P<0.05$ compared with DR5 MFI in the absence of nutlin-3. (C) rhTRAIL or D269H/E195R was added for $4 \mathrm{~h}$ following treatment with cisplatin $(1 \mu \mathrm{M})$ and nutlin-3 $(10 \mu \mathrm{M})$, and apoptosis levels were examined with acridine orange. At this low dose, cisplatin additively sensitised A2780 cells to combined nutlin-3 and D269H/E195R exposure. ${ }^{\star} P<0.05$, ${ }^{\star \star} P<0.01$ compared with untreated control. ${ }^{*} P<0.05$ apoptosis of combination compared with the effect of each single drug from the combination. ${ }^{\$} P<0.05$ triple combination compared with all other treatments. (D) Cell survival was measured using an MTT assay following $92 \mathrm{~h}$ continuous treatment. Treatment in the absence of rhTRAIL or D269H/E195R is set at 100\%. Nutlin-3 in combination with D269H/E195R more potently inhibited cell survival compared with the combination with rhTRAIL (upper panel). Addition of cisplatin $(0.25 \mu \mathrm{m})$ to the combination of nutlin-3 $(1 \mu \mathrm{M})$ and D269H/E195R had a stronger effect on cell survival (lower panel). ${ }^{\#} P<0.05$, ${ }^{\#} P<0.01$ combination compared with single rhTRAIL or D269H/E195R treatment. ${ }^{\$} P<0.05$ triple combination compared with D269H/ E195R plus cisplatin and with D269H/E195R plus nutlin-3 (1 $\mu \mathrm{m})$ treatment. Presented data are representative for at least three independent experiments.

cisplatin and D269H/E195R or nutlin-3 and D269H/E195R (Figure 5D lower panel, Supplementary Figure 2B).

We tested the possible apoptotic effects of the triple combination on the normal colon epithelial cell line NCM460. No significant activation of apoptosis was observed following 24-h treatment with all three drugs, indicating tumour cell-selective activity of the triple combination without harming normal cells (Supplementary Figure 3).

Combining nutlin-3, cisplatin and D269H/E195R massively induced apoptosis in an innovative living ex-patient model of primary human ovarian cancers. Finally, we evaluated whether our treatment modalities were effective in inducing apoptosis in primary ovarian tumour tissue cultured as ex vivo tissue slices. Apoptosis scoring based on H\&E staining showed excellent cell viability in controls following $24 \mathrm{~h}$ up to $72 \mathrm{~h}$ of culturing. Depending on the size of the specimen, variable numbers of slices were generated using the Krumdieck tissue slicer and treated for $24 \mathrm{~h}$ with treatment regimens as indicated. In a pilot experiment, D269H/E195R treatment induced more apoptosis compared with rhTRAIL (data not shown). Therefore, in the subsequent experiments, slices were treated with D269H/E195R, not with rhTRAIL. The tumour types of the tissue samples were as follows: clear cell ovarian cancer (different components, counted clear cell component, patient A) and serous ovarian cancer (patient B-D). Single treatment with cisplatin resulted in a significant induction of apoptosis in 4/4 tumours, with D269H/E195R in 2/4 tumours and with nutlin-3 in none of the tumours (Figure 6A). Combination treatment of D269H/E195R and nutlin-3 resulted in significantly higher apoptosis levels compared with D269H/E195R or nutlin-3 treatment alone in 4/4 tumours. No significant effect was observed when nutlin-3 was added to cisplatin in $3 / 3$ tumours. Upon combination of all three drugs, massive apoptosis induction occurred in $4 / 4$ tumours, which was significantly higher 

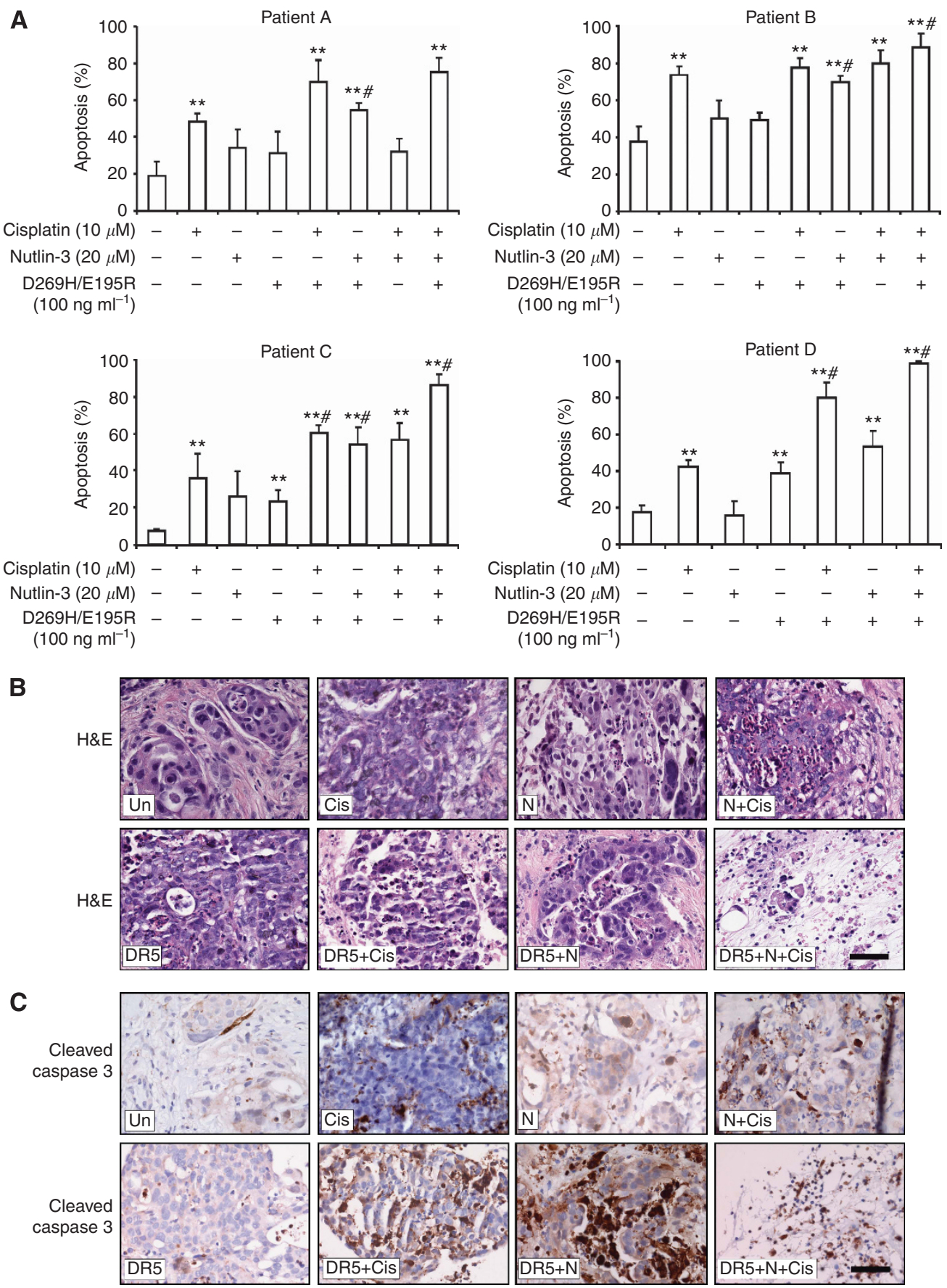

Figure 6. Combination of nutlin-3, cisplatin and D269H/E195R massively induced apoptosis in an ex vivo tissue slice model of primary human ovarian cancer. Tissue slices from primary human ovarian cancer tissue were treated with the indicated combinations for $24 \mathrm{~h}$. (A) Quantification of apoptosis levels based on H\&E scoring of each separate experiment. Tumour types: clear cell ovarian cancer (different components, counted clear cell component, patient A), and serous ovarian cancer (patient B, C and D). Single drug treatment induced moderate levels of apoptosis, which were enhanced substantially upon combination treatment. Combination of cisplatin, nutlin-3 and D269H/E195R further enhanced apoptosis with apoptosis in over $80 \%$ of cells. ${ }^{\star} P<0.05,{ }^{*} P<0.01$ compared with control (no drugs). \#P<0.05 compared with effect of each single drug used in the combination. (B) H\&E staining of a representative experiment showed excellent cell viability following $24 \mathrm{~h}$ incubation. Increased numbers of apoptotic cells can be seen following treatment with cisplatin (10 $\mu \mathrm{m})$, nutlin-3 $(20 \mu \mathrm{m})$, or D269H/E195R $\left(0.25 \mu \mathrm{g} \mathrm{ml}{ }^{-1}\right)$. Combined treatment further enhanced number of apoptotic cells and combination of all three drugs showed massive apoptosis induction with almost no viable cells left. (C) Representative active caspase 3 staining corresponding with the H\&E slides. The levels of active caspase 3 nicely correlate with the quantified number of apoptotic cells based on the H\&E stainings. (Un), no drugs added; (Cis), cisplatin; (N), nutlin-3;

(DR5), D269H/E195R. Bars indicate $50 \mu \mathrm{m}$.

than the effect of each drug alone in 3/4 tumours (Figure 6A). Next, we stained serial slides with $\mathrm{H} \& \mathrm{E}$ and for active caspase 3 (Figure $6 \mathrm{~B}$ and $\mathrm{C}$ ). Active caspase 3 levels correlated with the observed apoptosis levels based on H\&E staining as demonstrated by strong positive staining upon combination of drugs. In the triple combination active caspase 3 staining was less prominent, which is probably related to the late apoptotic stage of cells as reflected by the highly condensed nuclei in the H\&E staining. 


\section{DISCUSSION}

In the present paper, we showed that the MDM2-blocking agent nutlin-3 acts as an enhancer of TRAIL receptor-induced apoptosis in a p53-dependent manner. Moreover, the combination of nutlin3 with the DR5-selective TRAIL variant D269H/E195R was substantially more effective in inducing apoptosis than nutlin-3 combined with rhTRAIL. This was related to the nutlin-3dependent increase in DR5 expression. Adding cisplatin to the combination further enhanced apoptosis induction. Interestingly, nutlin-3 and D269H/E195R mildly induced caspase 3 cleavage and apoptosis as single agents in a novel living ex-patient model of primary human ovarian cancers. Combination of nutlin-3 and D269H/E195R induced more apoptosis and caspase 3 cleavage in these tumour tissue slices. Cisplatin was effective as single agent but even more effective in the triple combination treatment, which induced massive apoptosis in the tumour slices. As platinum-based chemotherapy is the cornerstone of ovarian cancer treatment, this illustrates the potential clinical relevance of our findings.

Approximately half of all human tumours express wild type p53, but these tumours often display a hampered p53 function, due to enhanced levels of MDM2 in complex with p53 (Vassilev, 2007). Via disruption of the MDM2-p53 complex, nutlin-3 effectively induced p53 levels in a panel of cancer cell lines carrying wild-type p53, resulting in apoptosis or cell cycle arrest in vitro as well as in vivo (Vassilev et al, 2004; Tovar et al, 2006; Koster et al, 2011). Nutlin-3 hardly induced apoptosis in our panel of wild-type p53 cell lines, which has been observed by others as well in a subgroup of cell lines (Tovar et al, 2006). This may be related to downstream defects in the p53-dependent intrinsic apoptosis pathway (Hougardy et al, 2005). We and others found that nutlin-3 increases promoter activity and membrane expression of DR5 (Secchiero et al, 2007; Hori et al, 2010). Nutlin-3 had no effect on DR4 or even decreased DR4 membrane expression in our panel of ovarian, lung and colon cell lines. Therefore, we explored the attractive strategy to combine nutlin-3 with drugs that induce apoptosis via the DR5-mediated extrinsic pathway, such as rhTRAIL (Secchiero et al, 2007; Hori et al, 2010). To fully exploit the effect of nutlin-3 on DR5, we used a DR5-selective TRAIL variant with mutations D296H and E195R (van der Sloot et al, 2006; Duiker et al, 2009). Indeed, nutlin-3 preferentially potentiated the effect of D269H/E195R over rhTRAIL not only in ovarian cancer cells but also in lung and colon cancer cells. Importantly, normal colon epithelial cells were not affected by the combination. D269H/E195R has a higher affinity for DR5 as compared with rhTRAIL, which may explain the increased efficacy of the combination with nutlin-3 (Szegezdi et al, 2012). This is supported by our finding that D269H/E195R in combination with nutlin-3 more potently activated caspase 8 - and caspase 9-induced caspase 3 cleavage.

DR5-specific targeting is an interesting antitumour strategy, as combinations of various drugs such as proteasome inhibitors or cisplatin with rhTRAIL more often upregulated DR5 than DR4 (Pennarun et al, 2010). In addition, high DR5 expression measured immunohistochemically in tumours of ovarian cancers patients correlated with poor patient survival and DR5 was upregulated following chemotherapy (Arts et al, 2004; Ouellet et al, 2007). Previously, we showed that cisplatin caused increased levels of p53 and DR5 membrane expression and enhanced rhTRAIL-induced apoptosis in ovarian cancer cell lines (Duiker et al, 2009; Duiker et al, 2011). Moreover, enhanced in vivo efficacy of D269H/E195R over rhTRAIL in combination with cisplatin was shown with an orthotopic A2780 bioluminescent xenograft model (Duiker et al, 2009). However, tumour growth resumed upon discontinuation of combined treatment. Thus, more potent combinations are warranted. Interestingly, cisplatin-induced p53 expression was not required for DR5 upregulation and rhTRAIL-sensitisation in A2780 cells (Duiker et al, 2011), in contrast to nutlin-3-induced p53 expression as shown in the present study. Nutlin-3 is known to enhance p53 levels without genotoxic effects (Vassilev, 2007). In order to benefit from the putative difference in p53 activation via cisplatin-induced DNA damage and nutlin-3, we included nutlin-3 in the ovarian cancer cell models. Accumulation of unphosphorylated p53 functions equally well as a transcription factor compared with DNA damage-induced phosphorylated p53 (Thompson et al, 2004), which was reflected in the nutlin-3induced DR5 upregulation. Upon combination of cisplatin and nutlin-3, massive p53 induction occurred, resulting in strong upregulation of p21, MDM2 and DR5. As a consequence, nutlin-3 rendered cells more susceptible to D269H/E195R as well as to D269H/E195R combined with cisplatin.

The in vitro results were translated into an innovative living ex vivo patient model of ovarian cancer. This model might be physiologically more relevant over in vitro cell line models and primary tumour cell cultures, as it takes tumour-stroma interactions into account. Moreover, heterogeneity of individual tumours and between the tumours can be evaluated. In concordance with our in vitro data, D269H/E195R was more potent than rhTRAIL as a single agent. Sensitivity to D269H/E195R was observed in two of the four tumours. An analogous observation was made with the anti-DR5 antibody TRA-8 that effectively induced apoptosis in most tumours tested using a similar ex vivo model of ovarian cancer (Estes et al, 2007; Frederick et al, 2009). Several in vitro studies have reported that ovarian cancer cell lines are intrinsically resistant to rhTRAIL (for review, refer to the study by Khaider et al, 2012). FLIP is an important candidate among others, causing rhTRAIL resistance in ovarian cancer cells, but other resistance mechanisms acting at the level of the DISC or more downstream on the apoptosis pathway have been identified (Duiker et al, 2011; Li et al, 2011; for reviews, refer to the studies by Mahalingam et al, 2009 and Pennarun et al, 2010). FLIP, caspase 8 and DR5 expression have been detected in the majority of ovarian cancer (Arts et al, 2004; Ouellet et al, 2007; Duiker et al, 2010; El-Gazzar et al, 2010). We and others found that many ex vivo ovarian tumours were sensitive to DR5-targeted drugs in contrast to the ovarian cancer cell line models, suggesting that FLIP expression is not the only determinant of resistance (Estes et al, 2007; Frederick; et al, 2009; Li et al, 2011). A recent study has shown that cisplatin augments the efficacy of the anti-DR5 antibody TRA-8 in the ex vivo model of ovarian cancer (Frederick et al, 2009). In the present study we found that combining D269H/E195R with nutlin3 sensitised all ex vivo ovarian tumours, resulting in higher apoptosis levels. Adding cisplatin to this combination further enhanced apoptosis. This is in line with our in vitro data, indicating that nutlin-3 and cisplatin additively enhanced D269H/E195Rinduced apoptosis via different mechanisms. However, it still remains to be determined what the key factors in the in vivo resistance to DR5-targeted drugs are and whether the triple combination will overcome all potential mechanisms of resistance in ovarian cancer.

In contrast to our previous and present in vitro data showing that cisplatin did not induce apoptosis in the A2780 cell line model (Duiker et al, 2009; Duiker et al, 2011), cisplatin treatment of the ex vivo ovarian cancer patient slices caused high levels of apoptosis in all four patient tumours. Although nutlin-3 treatment had no additional effect on cisplatin-induced apoptosis in tumour slices or A2780 cells, we clearly observed a stronger effect on A2780 cell survival with this combination after 4 days (Supplementary Figure 2B). Therefore, we may have underestimated the effect of cisplatin and nutlin-3 using these short-term apoptosis assays. Nutlin-3 and other MDM2 blockers are currently under clinical investigation in haematological malignancies and solid tumours (Brown et al, 2009). In wild-type p53-expressing tumour types 
such as testicular germ cell cancer, neuroblastoma and leukaemia, the additively enhanced apoptotic effects of this combination were demonstrated in in vitro models (Kojima et al, 2005; Barbieri et al, 2006; Vassilev, 2007; Bauer et al, 2010; Koster et al, 2011). Interestingly, nutlin-3 also enhanced chemotherapy-induced apoptosis in mutant p53-expressing cancer cells of various origins via activation of E2F1, thus extending the applicability of cisplatin and nutlin-3 to both wild type and mutant p53 cancer cells (Ambrosini et al, 2007). Further investigations are required to define the applicability of cisplatin and MDM2 inhibitor combinations for (ovarian) cancer treatment.

In conclusion, nutlin-3 is a potent enhancer of rhTRAIL- and especially D269H/E195R-induced apoptosis in wild-type p53expressing cancer cells. Adding DNA-damaging agents such as cisplatin to the combination further enhances DR5-mediated apoptosis. Therefore, this combination could provide an effective treatment for (sub)groups of ovarian, colon and lung cancer expressing wild-type $\mathrm{p} 53$.

\section{ACKNOWLEDGEMENTS}

This work was performed within the framework of Dutch Top Institute Pharma, project 'TNF-ligands in cancer' project no. T3-112. We thank Inge AM de Graaf and Marina H de Jager for excellent technical assistance. We thank Dr Robbert Cool and Dr Carlos Reis for producing the DR5-selective TRAIL (D269H/ E195R).

\section{CONFLICT OF INTEREST}

WJQ is the founder of Triskel Therapeutics that has patented the TRAIL variant D269H/E195R. All other authors declare no conflict of interest.

\section{REFERENCES}

Adams C, Totpal K, Lawrence D, Marsters S, Pitti R, Yee S, Ross S, DeForge L, Koeppen H, Sagolla M, Compaan D, Lowman H, Hymowitz S, Ashkenazi A (2008) Structural and functional analysis of the interaction between the agonistic monoclonal antibody Apomab and the proapoptotic receptor DR5. Cell Death Differ 15: 751-761.

Adams JM, Cory S (2007) The Bcl-2 apoptotic switch in cancer development and therapy. Oncogene 26: 1324-1337.

Ambrosini G, Sambol EB, Carvajal D, Vassilev LT, Singer S, Schwartz GK (2007) Mouse double minute antagonist Nutlin-3a enhances chemotherapy-induced apoptosis in cancer cells with mutant $\mathrm{p} 53$ by activating E2F1. Oncogene 26: 3473-3481.

Arts HJ, de Jong S, Hollema H, ten Hoor KA, van der Zee AG, de Vries EG (2004) Chemotherapy induces death receptor 5 in epithelial ovarian carcinoma. Gynecol Oncol 92: 794-800.

Ashcroft M, Vousden KH (1999) Regulation of p53 stability. Oncogene 18: 7637-7643.

Ashkenazi A, Pai RC, Fong S, Leung S, Lawrence DA, Marsters SA, Blackie C, Chang L, McMurtrey AE, Hebert A, DeForge L, Koumenis IL, Lewis D, Harris L, Bussiere J, Koeppen H, Shahrokh Z, Schwall RH (1999) Safety and antitumor activity of recombinant soluble Apo2 ligand. J Clin Invest 104: $155-162$.

Barbieri E, Mehta P, Chen Z, Zhang L, Slack A, Berg S, Shohet JM (2006) MDM2 inhibition sensitizes neuroblastoma to chemotherapy-induced apoptotic cell death. Mol Cancer Ther 5: 2358-2365.

Bauer S, Muhlenberg T, Leahy M, Hoiczyk M, Gauler T, Schuler M, Looijenga L (2010) Therapeutic potential of Mdm2 inhibition in malignant germ cell tumours. Eur Urol 57: 679-687.

Bond GL, Hu W, Levine AJ (2005) MDM2 is a central node in the p53 pathway: 12 years and counting. Curr Cancer Drug Targets 5: 3-8.
Brown CJ, Lain S, Verma CS, Fersht AR, Lane DP (2009) Awakening guardian angels: drugging the p53 pathway. Nat Rev Cancer 9: 862-873.

de Graaf IA, Olinga P, de Jager MH, Merema MT, de Kanter R, van de Kerkhof EG, Groothuis GM (2010) Preparation and incubation of precision-cut liver and intestinal slices for application in drug metabolism and toxicity studies. Nat Protoc 9: 1540-1551.

den Hollander MW, Gietema JA, de Jong S, Walenkamp AM, Reyners AK, Oldenhuis CN, de Vries EG (2013) Translating TRAIL-receptor targeting agents to the clinic. Cancer Lett 332: 194-201.

Duiker EW, de Vries EG, Mahalingam D, Meersma GJ, Boersma-van EW, Hollema H, Lub-de Hooge MN, van Dam GM, Cool RH, Quax WJ, Samali A, van der Zee AG, de Jong S (2009) Enhanced antitumor efficacy of a DR5-specific TRAIL variant over recombinant human TRAIL in a bioluminescent ovarian cancer xenograft model. Clin Cancer Res 15: 2048-2057.

Duiker EW, Meijer A, van der Bilt AR, Meersma GJ, Kooi N, van der Zee AG, de Vries EG, de Jong S (2011) Drug-induced caspase 8 upregulation sensitises cisplatin-resistant ovarian carcinoma cells to rhTRAIL-induced apoptosis. Br J Cancer 104: 1278-1287.

Duiker EW, van der Zee AG, de Graeff P, Boersma-van EW, Hollema H, de Bock GH, de Jong S, de Vries EG (2010) The extrinsic apoptosis pathway and its prognostic impact in ovarian cancer. Gynecol Oncol 116: 549-555.

El-Gazzar A, Wittinger M, Perco P, Anees M, Horvat R, Mikulits W, Grunt TW, Mayer B, Krainer M (2010) The role of c-FLIP(L) in ovarian cancer: chaperoning tumor cells from immunosurveillance and increasing their invasive potential. Gynecol Oncol 117: 451-459.

Estes JM, Oliver PG, Straughn Jr. JM, Zhou T, Wang W, Grizzle WE, Alvarez RD, Stockard CR, LoBuglio AF, Buchsbaum DJ (2007) Efficacy of anti-death receptor 5 (DR5) antibody (TRA-8) against primary human ovarian carcinoma using a novel ex vivo tissue slice model. Gynecol Oncol 105: 291-298.

Frederick PJ, Kendrick JE, Straughn Jr JM, la Manna DL, Oliver PG, Lin HY, Grizzle WE, Stockard CR, Alvarez RD, Zhou T, LoBuglio AF, Buchsbaum DJ (2009) Effect of TRA-8 anti-death receptor 5 antibody in combination with chemotherapy in an ex vivo human ovarian cancer model. Int J Gynecol Cancer 19: 814-819.

Herbst RS, Eckhardt SG, Kurzrock R, Ebbinghaus S, O’Dwyer PJ, Gordon MS, Novotny W, Goldwasser MA, Tohnya TM, Lum BL, Ashkenazi A, Jubb AM, Mendelson DS (2010) Phase I dose-escalation study of recombinant human Apo2L/TRAIL, a dual proapoptotic receptor agonist, in patients with advanced cancer. J Clin Oncol 28: 2839-2846.

Hori T, Kondo T, Kanamori M, Tabuchi Y, Ogawa R, Zhao QL, Ahmed K, Yasuda T, Seki S, Suzuki K, Kimura T (2010) Nutlin-3 enhances tumor necrosis factor-related apoptosis-inducing ligand (TRAIL)-induced apoptosis through up-regulation of death receptor 5 (DR5) in human sarcoma HOS cells and human colon cancer HCT116 cells Cancer Lett 287: 98-108.

Hougardy BM, Maduro JH, van der Zee AG, Willemse PH, de Jong S, de Vries EG (2005) Clinical potential of inhibitors of survival pathways and activators of apoptotic pathways in treatment of cervical cancer: changing the apoptotic balance. Lancet Oncol 6: 589-598.

Hougardy BM, Reesink-Peters N, van den Heuvel FA, ten Hoor KA, Hollema H, de Vries EG, de Jong S, van der Zee AG (2008) A robust ex vivo model for evaluation of induction of apoptosis by rhTRAIL in combination with proteasome inhibitor MG132 in human premalignant cervical explants. Int J Cancer 123: 1457-1465.

Ichikawa K, Liu W, Zhao L, Wang Z, Liu D, Ohtsuka T, Zhang H, Mountz JD, Koopman WJ, Kimberly RP, Zhou T (2001) Tumoricidal activity of a novel anti-human DR5 monoclonal antibody without hepatocyte cytotoxicity. Nat Med 7: 954-960.

Kelley RF, Totpal K, Lindstrom SH, Mathieu M, Billeci K, DeForge L, Pai R, Hymowitz SG, Ashkenazi A (2005) Receptor-selective mutants of apoptosis-inducing ligand 2/tumor necrosis factor-related apoptosisinducing ligand reveal a greater contribution of death receptor (DR) 5 than DR4 to apoptosis signaling. J Biol Chem 280: 2205-2212.

Khaider NG, Lane D, Matte I, Rancourt C, Piche A (2012) Targeted ovarian cancer treatment: the TRAILs of resistance. Am J Cancer Res 2: 75-92.

Kojima K, Konopleva M, Samudio IJ, Shikami M, Cabreira-Hansen M, McQueen T, Ruvolo V, Tsao T, Zeng Z, Vassilev LT, Andreeff M (2005) MDM2 antagonists induce p53-dependent apoptosis in AML: implications for leukemia therapy. Blood 106: 3150-3159. 
Koster R, Timmer-Bosscha H, Bischoff R, Gietema JA, de Jong S (2011) Disruption of the MDM2-p53 interaction strongly potentiates p53-dependent apoptosis in cisplatin-resistant human testicular carcinoma cells via the Fas/FasL pathway. Cell Death Dis 2: e148.

Levine AJ, Oren M (2009) The first 30 years of p53: growing ever more complex. Nat Rev Cancer 9: 749-758.

Li J, Knee DA, Wang YZ, Zhang QX, Johnson JA, Cheng J, He H, Miller C, Li ZF, Kowal C, Eckman J, Tang B, Yuan J, Chen L, Deveraux Q, Nasoff MS, Stover D (2008) LBY135, a novel anti-DR5 agonistic antibody induces tumor cell-specific cytotoxic activity in human colon tumor cell lines and xenografts. Drug Dev Res 69: 69-82.

Li LC, Jayaram S, Ganesh L, Qian L, Rotmensch J, Maker AV, Prabhakar BS (2011) Knockdown of MADD and c-FLIP overcomes resistance to TRAIL-induced apoptosis in ovarian cancer cells. Am J Obstet Gynecol 205: 362.e12-25.

Mahalingam D, Szegezdi E, Keane M, de Jong S, Samali A (2009) TRAIL receptor signalling and modulation: Are we on the right TRAIL? Cancer Treat Rev 35: 280-288.

Ouellet V, Le PC, Madore J, Guyot MC, Barres V, Lussier C, Tonin PN, Provencher DM, Mes-Masson AM (2007) An apoptotic molecular network identified by microarray: on the TRAIL to new insights in epithelial ovarian cancer. Cancer 110: 297-308.

Pennarun B, Meijer A, de Vries EG, Kleibeuker JH, Kruyt F, de Jong S (2010) Playing the DISC: turning on TRAIL death receptor-mediated apoptosis in cancer. Biochim Biophys Acta 1805: 123-140.

Pitti RM, Marsters SA, Ruppert S, Donahue CJ, Moore A, Ashkenazi A (1996) Induction of apoptosis by Apo-2 ligand, a new member of the tumor necrosis factor cytokine family. J Biol Chem 271: 12687-12690.

Pukac L, Kanakaraj P, Humphreys R, Alderson R, Bloom M, Sung C, Riccobene T, Johnson R, Fiscella M, Mahoney A, Carrell J, Boyd E, Yao XT, Zhang L, Zhong L, von KA, Shepard L, Vaughan T, Edwards B, Dobson C, Salcedo T, Albert V (2005) HGS-ETR1, a fully human TRAIL-receptor 1 monoclonal antibody, induces cell death in multiple tumour types in vitro and in vivo. Br J Cancer 92: $1430-1441$

Reis CR, van der Sloot AM, Natoni A, Szegezdi E, Setroikromo R, Meijer M, Sjollema K, Stricher F, Cool RH, Samali A, Serrano L, Quax WJ (2010) Rapid and efficient cancer cell killing mediated by high-affinity death receptor homotrimerizing TRAIL variants. Cell Death Dis 1: e83.

Reis CR, van der Sloot AM, Szegezdi E, Natoni A, Tur V, Cool RH, Samali A, Serrano L, Quax WJ (2009) Enhancement of antitumor properties of rhTRAIL by affinity increase toward its death receptors (dagger). Biochemistry 48: 2180-2191.

Secchiero P, Zerbinati C, di Iasio MG, Melloni E, Tiribelli M, Grill V, Zauli G (2007) Synergistic cytotoxic activity of recombinant TRAIL plus the nongenotoxic activator of the p53 pathway nutlin-3 in acute myeloid leukemia cells. Curr Drug Metab 8: 395-403.

Soria JC, Mark Z, Zatloukal P, Szima B, Albert I, Juhasz E, Pujol JL, Kozielski J, Baker N, Smethurst D, Hei YJ, Ashkenazi A, Stern H, Amler L, Pan Y, Blackhall F (2011) Randomized phase II study of dulanermin in combination with paclitaxel, carboplatin, and bevacizumab in advanced non-small-cell lung cancer. J Clin Oncol 29: 4442-4451.

Subbiah V, Brown RE, Buryanek J, Trent J, Ashkenazi A, Herbst R, Kurzrock R (2012) Targeting the apoptotic pathway in chondrosarcoma using recombinant human Apo2L/TRAIL (Dulanermin), a dual proapoptotic receptor (DR4/DR5) agonist. Mol Cancer Ther 11: 2541-2546.

Szegezdi E, van der Sloot AM, Mahalingam D, O’Leary L, Cool RH, Munoz IG, Montoya G, Quax WJ, de Jong S, Samali A, Serrano L (2012) Kinetics in signal transduction pathways involving promiscuous oligomerizing receptors can be determined by receptor specificity: apoptosis induction by TRAIL. Mol Cell Proteomics 11: M111.

Thompson T, Tovar C, Yang H, Carvajal D, Vu BT, Xu Q, Wahl GM, Heimbrook DC, Vassilev LT (2004) Phosphorylation of p53 on key serines is dispensable for transcriptional activation and apoptosis. J Biol Chem 279: 53015-53022.

Timmer-Bosscha H, Timmer A, Meijer C, de Vries EG, de Jong B, Oosterhuis JW, Mulder NH (1993) cis-diamminedichloroplatinum(ii) resistance in vitro and in vivo in human embryonal carcinoma cells. Cancer Res 53: 5707-5713.

Tovar C, Rosinski J, Filipovic Z, Higgins B, Kolinsky K, Hilton H, Zhao X, Vu BT, Qing W, Packman K, Myklebost O, Heimbrook DC, Vassilev LT (2006) Small-molecule MDM2 antagonists reveal aberrant p53 signaling in cancer: implications for therapy. Proc Natl Acad Sci USA 103: 1888-1893.

Tur V, van der Sloot AM, Reis CR, Szegezdi E, Cool RH, Samali A, Serrano L, Quax WJ (2008) DR4-selective tumor necrosis factor-related apoptosisinducing ligand (TRAIL) variants obtained by structure-based design. J Biol Chem 283: 20560-20568.

van der Sloot AM, Tur V, Szegezdi E, Mullally MM, Cool RH, Samali A, Serrano L, Quax WJ (2006) Designed tumor necrosis factor-related apoptosis-inducing ligand variants initiating apoptosis exclusively via the DR5 receptor. Proc Natl Acad Sci USA 103: 8634-8639.

Vassilev LT (2007) MDM2 inhibitors for cancer therapy. Trends Mol Med 13: 23-31.

Vassilev LT, Vu BT, Graves B, Carvajal D, Podlaski F, Filipovic Z, Kong N, Kammlott U, Lukacs C, Klein C, Fotouhi N, Liu EA (2004) In vivo activation of the p53 pathway by small-molecule antagonists of MDM2. Science 303: 844-848.

Vousden KH, Lane DP (2007) p53 in health and disease. Nat Rev Mol Cell Biol 8: 275-283.

Walczak H, Sprick MR (2001) Biochemistry and function of the DISC. Trends Biochem Sci 26: 452-453.

Wiley SR, Schooley K, Smolak PJ, Din WS, Huang CP, Nicholl JK, Sutherland GR, Smith TD, Rauch C, Smith CA (1995) Identification and characterization of a new member of the TNF family that induces apoptosis. Immunity 3: 673-682.

Wu GS, Burns TF, McDonald III ER, Jiang W, Meng R, Krantz ID, Kao G, Gan DD, Zhou JY, Muschel R, Hamilton SR, Spinner NB, Markowitz S, Wu G, El-Deiry WS (1997) KILLER/DR5 is a DNA damage-inducible p53-regulated death receptor gene. Nat Genet 17: 141-143.

Zhang Z, Zhang R (2005) p53-independent activities of MDM2 and their relevance to cancer therapy. Curr Cancer Drug Targets 5: 9-20.

This work is published under the standard license to publish agreement. After 12 months the work will become freely available and the license terms will switch to a Creative Commons AttributionNonCommercial-Share Alike 3.0 Unported License.

Supplementary Information accompanies this paper on British Journal of Cancer website (http://www.nature.com/bjc) 